\title{
Assessment of Fatigue Life and Stiffness of Asphalt Concrete After Implementation of Additives
}

\author{
Saad Issa Sarsam \\ ${ }^{1}$ Sarsam and Associates Consult Bureau (SACB), Baghdad-IRAQ. Formerly at Department of Civil Engineering, College of \\ Engineering, University of Baghdad, Iraq
}

\section{Keywords}

\section{Asphalt concrete,}

Flexural Stiffness, Fatigue life,

Fly ash,

Silica fumes.

\begin{abstract}
Modifying asphalt binder with additives can enhance the overall physical properties of asphalt concrete. In the present investigation, an attempt has been made to use $2 \%$ of silica fumes and $4 \%$ of fly ash class $\mathrm{F}$ for modification of asphalt binder in wet process. Asphalt concrete wearing course slab samples have been prepared under roller compaction. The beam specimens of $400 \mathrm{~mm}$ length and $50 \mathrm{~mm}$ height and $63 \mathrm{~mm}$ width were extracted from the slab samples. The beam specimens were subjected to the four-point repeated flexural bending beam test. The flexural stiffness was calculated under three constant micro strain levels of $(250,400$, and 750$)$. The fatigue life was monitored in terms the number of load repetitions to reach the required reduction in stiffness of $50 \%$. It was concluded that the flexural stiffness increases by (11, and 15) \%, (17.7, and 63.6) $\%,(57.2$, and 65$) \%$ when $2 \%$ of silica fumes or $4 \%$ of fly ash are implemented and the specimen's practices 750,400 , and 250 micro strain levels respectively. However, the fatigue life increases by (40, and 72.8$) \%$, (115, and 220.6$) \%$, (46, and 94.6 ) \% when $2 \%$ of silica fumes or $4 \%$ of fly ash are implemented and the specimen's practices 750,400 , and 250 micro strain levels respectively. It is recommended to use modified binder with silica fumes and fly ash in asphalt concrete to enhance the fatigue life and stiffness.
\end{abstract}

\section{Introduction}

Adhikari and You, [1] used beam fatigue test to evaluate the flexural stiffness and fatigue life of the asphalt concrete beam specimens. A constant strain level of 400, 300, and 200 micro strains and frequency level of $10 \mathrm{~Hz}, 5 \mathrm{~Hz}$, and $1 \mathrm{~Hz}$, have been implemented. It was revealed that fatigue life was low when the asphalt concrete beam was tested with high strain level and high loading frequency. Fatigue life was high at low strain level and low loading frequency. Kakade et al., [2] explores the effect of different proportions of hydrated lime on the rutting performance of bituminous mixes. The rutting characteristics of unmodified and lime modified binders were evaluated in terms of Superpave binder rutting parameter. It was concluded that rutting performance of mixes improved significantly by lime modification. It was also observed that the beneficial effect of lime addition in reducing rutting (which is a high temperature phenomenon) was realized more at higher mix temperatures. Al-Mohammedawi and Mollenhauer, [3] identified the influence of active fillers such as limestone, cement, ladle slag, and silica fume on the rheological properties and the resulting fatigue behavior of cold bitumen emulsion mastic. The assessment was supported by chemical analysis for the filler-bitumen emulsion. Bitumen emulsion was mixed separately with the fillers to prepare the mastics. Results show that the rheological performance and the fatigue damage resistance depend not only on the filler inclusions but also on filler type and chemistry. The addition of mineral fillers can significantly change the rheological response and fatigue damage resistance of the mastic as reported by Lesueur et al., [4]. Buczy et al., [5] stated that mineral fillers can be chemically grouped into active and inactive fillers, depending on their reactivity within bitumen emulsion. Limestone, which is considered as inert filler, is classified as inactive fillers because of the mineral composition and is usually employed as a stiffness regulator by adding solid particles to the binder matrix. As little or no chemical reaction is expected, it maintains the viscoelastic response. Underwood and Kim, [6] reported that fillers strengthen bitumen through the three main mechanisms of particle geometry, volume Corresponding Author:

saadisasarsam@coeng.uobaghdad.edu.iq (S.I.Sarsam Orcid: 0000-0001-8426-5767) filling, and chemical interaction. Particle geometry and volume filling are considered as mechanical reinforcement, while volume filling is caused by adding more solid particles to the system, resulting in high stiffness. Khan et al., [7] investigated the effects of different fillers on some properties of asphalt concrete mixtures. Two filler types, silica fumes and marble dust were used to investigate the effect of filler / asphalt ratio on the characteristics of asphalt mixtures. It was concluded that the mixtures with 50\% silica fume and 50\% marble dust have greater stability than all the other percentages used in a Marshall mix. It has also void content of 6.8 which is within the specification. All other air voids results are out of range. All other percentages of filler have lower stability and voids which are out of range. Mixture having 50\% silica \& 50\% marble dust has only $13.5 \mathrm{~mm}$ flow value which is greater than all other percentages. Ullah et al., [8] investigated two substitution fillers (Cement and Lime) which were used with two different aggregate quarries (based on minerals composition) to evaluate the relatively most beneficial combination of both fillers as well as an aggregate quarry to enhance the performance life of asphalt pavements. It was concluded that replacement of aggregate filler with hydrated lime and cement has a beneficial effect on asphalt mix performance. Substitution filler improves the hightemperature rut performance and intermediate temperature fatigue performance of asphaltic concrete mixture up to $25 \%$ to that of the conventional mixture. At the same time, substitution filler has improved $70 \%$ of adhesion properties to that of the conventional mixture. The addition of different fillers such as hydrated lime, fly ash, silica fume, cement, and bag-house fines are known to increase the rut resistance of asphalt mixture as stated by Bahia et al., [9]. Wang et al., [10] concluded in his research that the use of cement with filler material in asphalt concrete mixture can improve stiffness, stripping resistance, and strength of asphalt concrete mixture. Cement has a similar effect to that of mineral filler on volumetric and physical properties of asphalt mixture. Sarsam, [11] concluded that the stiffness of asphalt concrete is susceptible to aging, the increase in Micro strain level leads into a remarkable decrease in initial and failure stiffness's. The stiffness is susceptible to the testing 
temperature and asphalt content, lower testing temperature of $5 \circ \mathrm{C}$ exhibits higher stiffness value, while higher binder content has a negative impact on the stiffness. Sarsam and AL-Lamy, [12] revealed that the Fatigue life of asphalt concrete increased with the use of silica fumes and fly ash by (50\% and 111\%) and stiffness increased by (124\% and 155\%), respectively, as compared with conventional mix. Estimation of fatigue lives of bituminous mixtures using artificial neural networks was conducted by Tapkin, [13]. Different types of fly ash were implemented as filler partial replacement agents in a dense bituminous mixture. Fatigue tests were conducted using repeated load indirect tensile test under controlled stress conditions. For determination of fatigue life, the initiation of macro crack was accepted as the main criteria to terminate the test.

The aim of the present investigation, an attempt has been made to use $2 \%$ of silica fumes and $4 \%$ of fly ash class $\mathrm{F}$ for modification of asphalt binder in wet process. The influence of such additives on flexural stiffness and fatigue life will be assessed.

\section{Materials and methods}

The materials implemented in the present investigation are locally available and are widely used in asphalt pavement construction.

\subsection{Asphalt cement}

Asphalt cement of penetration grad 40-50 was implemented in this work. It was obtained from AL-Nasiriya Refinery. The physical properties of asphalt binder are listed in Table 1.

Table 1. Physical Properties of Asphalt Cement Binder

\begin{tabular}{|c|c|c|c|}
\hline Physical properties & $\begin{array}{l}\text { ASTM, } \\
\text { Designation }\end{array}$ & $\begin{array}{l}\text { Asphalt } \\
\text { cement }\end{array}$ & $\begin{array}{l}\text { SCRB, } \\
{[15]}\end{array}$ \\
\hline Penetration & D5-06 & 42 & $40-50$ \\
\hline Softening Point ${ }^{\circ} \mathrm{C}$ & D36-95 & 49 & - \\
\hline Ductility Cm & D113-99 & $100+$ & $>100$ \\
\hline Specific Gravity & D70 & 1.04 & - \\
\hline Flash Point ${ }^{\circ} \mathrm{C}$ & D92-05 & 269 & $>232$ \\
\hline $\begin{array}{l}\text { Retained Penetration of } \\
\text { Residue }\end{array}$ & D5-06 & 33 & $<55$ \\
\hline $\begin{array}{l}\text { Loss in weight }\left(163^{\circ} \mathrm{C} \text {, }\right. \\
50 \mathrm{~g}, 5 \mathrm{~h}) \%\end{array}$ & D-1754 & 0.175 & --- \\
\hline Ductility of Residue & D113-99 & $130 \mathrm{~cm}$ & $>25$ \\
\hline
\end{tabular}

\subsection{Fine and coarse aggregates}

Crushed coarse aggregates having a nominal maximum size of $19 \mathrm{~mm}$ (retained on sieve No. 4) was obtained from AL-Ukhaider quarry. Crushed and natural sand mixture was implemented as Fine aggregate (passing sieve No.4 and retained on sieve No.200). It was obtained from the same source. The aggregates were washed, then air dried and separated into different sizes by sieving. The physical properties of aggregates are demonstrated in Table 2.

Table 2. Physical Properties of Coarse and Fine Aggregate as per ASTM, [14]

\begin{tabular}{|c|c|c|}
\hline Property & $\begin{array}{l}\text { Coarse } \\
\text { Aggregate }\end{array}$ & $\begin{array}{l}\text { Fine } \\
\text { Aggregate }\end{array}$ \\
\hline $\begin{array}{l}\text { Bulk Specific Gravity (ASTM C } 127 \\
\text { and C 128). }\end{array}$ & 2.642 & 2.658 \\
\hline $\begin{array}{l}\text { Percent Water Absorption (ASTM C } \\
127 \text { and C 128) }\end{array}$ & 1.07 & 1.83 \\
\hline $\begin{array}{l}\text { Percent Wear (Los-Angeles } \\
\text { Abrasion) (ASTM C 131) }\end{array}$ & $18 \%$ & - \\
\hline
\end{tabular}

\subsection{Mineral filler}

The mineral filler implemented in the present investigation is the limestone dust which was obtained from Karbala governorate. The filler passes sieve No.200 $(0.075 \mathrm{~mm})$. The physical properties of the mineral filler are presented in Table 3.

Table 3. Physical Properties of Mineral Filler

\begin{tabular}{ll}
\hline Property & Value \\
\hline Bulk specific gravity & 2.617 \\
$\%$ Passing Sieve No.200 & 94 \\
\hline
\end{tabular}

\subsection{Fly ash}

Fly ash of class $\mathrm{F}$ was obtained from local market. The physical properties of fly ash are listed in Table 4, while the chemical composition of Fly Ash is listed in Table 5.

Table 4. Physical Properties of Fly Ash

\begin{tabular}{cccc}
\hline $\begin{array}{c}\text { Maximum Sieve } \\
\text { size (micron) }\end{array}$ & \% Passing & $\begin{array}{c}\text { Specific } \\
\text { gravity }\end{array}$ & $\begin{array}{c}\text { Specific surface } \\
\text { area (m2/kg) }\end{array}$ \\
\hline 0.075 & 98 & 2.645 & 650 \\
\hline
\end{tabular}

Table 5. Chemical Composition of Fly Ash

\begin{tabular}{ccc}
\hline Chemical composition & Percent & $\begin{array}{c}\text { ASTM C-618, [14] } \\
\text { Requirement }\end{array}$ \\
\hline $\mathrm{SiO} 2$ & 61.95 & $\ldots . .$. \\
$\mathrm{Fe} 2 \mathrm{O} 3$ & 2.67 & $\ldots . .$. \\
$\mathrm{Al} 2 \mathrm{O} 3$ & 28.82 & $\ldots . .$. \\
$\mathrm{CaO}$ & 0.88 & $\ldots .$. \\
$\mathrm{MgO}$ & 0.34 & $5.0 \mathrm{max}$ \\
$\mathrm{Na2O}$ & 0.26 & $1.5 \mathrm{max}$ \\
Loss on ignition & 0.86 & $6.0 \mathrm{max}$ \\
\hline
\end{tabular}

\subsection{Silica fumes}

Silica fumes was manufactured by Wacker Silicon Company in Germany as fluffy powder, it was obtained from local market; Table 6 presents its physical properties. Table 7 shows the chemical composition of the Silica fumes.

Table 6. Physical Properties of Silica Fumes

\begin{tabular}{cccc}
\hline Maximum sieve size & $\begin{array}{c}\mathrm{PH} \\
\text { value }\end{array}$ & $\begin{array}{c}\text { Density } \\
(\mathrm{kg} / \mathrm{m} 3)\end{array}$ & $\begin{array}{c}\text { Specific surface } \\
\text { area }(\mathrm{m} 2 / \mathrm{kg})\end{array}$ \\
\hline Passing sieve $(0.075 \mathrm{~mm})$ & 4.5 & 2.6455 & 200000 \\
\hline
\end{tabular}

Table 7. Chemical Components of Silica Fumes

\begin{tabular}{cc}
\hline Chemical Composition & Percent \\
\hline $\mathrm{SiO} 2$ & 99.1 \\
$\mathrm{Fe} 2 \mathrm{O} 3$ & 35.0 P.P.M \\
$\mathrm{Al} 2 \mathrm{O} 3$ & $<0.035$ \\
$\mathrm{TiO} 2$ & $<0.006$ \\
$\mathrm{CaO} 2$ & 0.03 \\
$\mathrm{MgO}$ & 52.0 P.P.M \\
$\mathrm{SO} 3$ & $<0.07$ \\
Loss on ignition & 0.7 \\
\hline
\end{tabular}




\subsection{Selection of aggregates combined gradation}

The selected aggregates gradation in the present investigation follows SCRB, [15] specification for dense graded wearing course pavement layer. It has $12.5 \mathrm{~mm}$ nominal maximum size of aggregates. Table 8 shows the selected aggregate gradation.

Table 8. Gradation of Aggregate for Wearing Course as per SCRB, [15]

\begin{tabular}{llll}
\hline Sieve size mm & Selected gradation & $\begin{array}{l}\text { SCRB, } \\
\text { Specifications }\end{array}$ & [15] \\
\hline 19 & 100 & 100 \\
12.5 & 95 & $95-100$ \\
9.5 & 83 & $76-90$ \\
4.75 & 59 & $44-74$ \\
2.36 & 43 & $28-58$ \\
0.3 & 12 & $5-12$ \\
0.075 & 7 & $4-10$ \\
\hline
\end{tabular}

\subsection{Preparation of modified asphalt cement}

Modified asphalt binder is prepared by using the wet process. In the wet process, asphalt cement was heated to $150{ }^{\circ} \mathrm{C}$ and then the fly ash or silica fumes were added in powder form using various percentages of each additive. The mixture was blended in a mixer at a blending speed of about $1300 \mathrm{rpm}$ and the mixing temperatures of $160{ }^{\circ} \mathrm{C}$ was maintained for 20 minutes to promote the chemical and physical bonding of the components. The optimum percentages of fly ash and Silica fumes are ( 4 and 2 ) \% by weight of binder respectively. Details of the mixing procedure and selection of the optimum percentages could be found in Sarsam and Al-Lamy, [12].

\subsection{Preparation of asphalt concrete mixture and specimens}

The coarse and fine aggregates were combined with mineral filler to meet the specified gradation for wearing course. The combined aggregates were then heated to $160{ }^{\circ} \mathrm{C}$ before mixing with asphalt cement. The asphalt cement or the modified asphalt binder was heated to $150 \circ \mathrm{C}$ to produce a kinematic viscosity of $(170 \pm 20)$ centistokes as recommended by SCRB, [15]. Then, the binder was added to the heated aggregate to achieve the desired amount and mixed thoroughly by hand using a spatula for two minutes until all aggregate particles were coated with the binder. The mixture was subjected to short-term ageing process for 4 hours at temperature of $135{ }^{\circ} \mathrm{C}$ according to AASHTO R-30, [16]. The optimum asphalt content of $4.9 \%$ was implemented. The optimum binder percentage was determined based on Marshall trial mixes using various asphalt percentages. Details of obtaining the optimum binder content could be found in Sarsam and Alwan, [17]. The short-term aged mixtures were casted in a slab mold of $(40 \times 30 \times 6) \mathrm{cm}$ and subjected to roller compaction to the target bulk density for each binder type according to EN12697-33, [18]. The applied static load was $5 \mathrm{kN}$ while the number of load passes depended on the asphalt type in mixture and was determined based on trial-and-error process. Details of the compaction process could be referred to Sarsam, [11]. The compaction temperature was maintained to $150{ }^{\circ} \mathrm{C}$. Slab samples were left to cool overnight. Beam specimens of $50 \pm 2 \mathrm{~mm}$ high, $63 \pm 2 \mathrm{~mm}$ wide and 400 $\mathrm{mm}$ length were obtained from the compacted slab sample using the Diamond-saw. The total number of beam specimens obtained was twelve, while the number of casted slabs was three.

\subsection{Repeated flexural bending beam test}

The four-point repeated flexural bending beam test according to AASHTO T321, [16] was implemented to identify the influence of additives on the fatigue life and flexural stiffness of asphalt concrete beam specimens at intermediate pavement operating temperature of $20{ }^{\circ} \mathrm{C}$ and under constant strain level. During the flexural fatigue test, the beam is subjected to repeated four-point loading. The load frequency is usually set $5 \mathrm{~Hz}$, and the deflection caused by the loading is measured at the center of the beam. The test was terminated when the beam has reached a 50 percent reduction in stiffness. A repeated haversine (sinusoidal) load is applied to the two inner clamps on the beam specimen with the outer clamps providing a reaction load. This setup produces a constant bending moment over the center portion of the beam (between the two inside clamps). Beams were subjected to a repeated load at a constant strain level. Three different Micro strain levels of 250,400 , and 750 were tried to simulate various modes of loading in the field.

\section{Results and discussions}

\subsection{Influence of additives on flexural stiffness of asphalt concrete}

As demonstrated in Figure 1, implementation of additives exhibits positive influence on the flexural stiffness regardless of the micro strain level implemented. However, as the strain level increases, the flexural stiffness decreases regardless of the additives implemented. The flexural stiffness increases by (11, and 15) \%, (17.7, and 63.6) \%, (57.2, and 65) $\%$ when $2 \%$ of silica fumes or $4 \%$ of fly ash are implemented and the specimen's practices 750, 400, and 250 micros train levels respectively. On the other hand, when the strain level decline from 250 to 400 and 750, the flexural stiffness declines by (60.3, and 71.4), (70.3, and 79.7), (60.7, and 80) for control, modified mixture with $2 \%$ silica fumes and modified mixture with $4 \%$ fly ash respectively. Similar finding was reported by Bahia et al., [9] and Sarsam, [11].

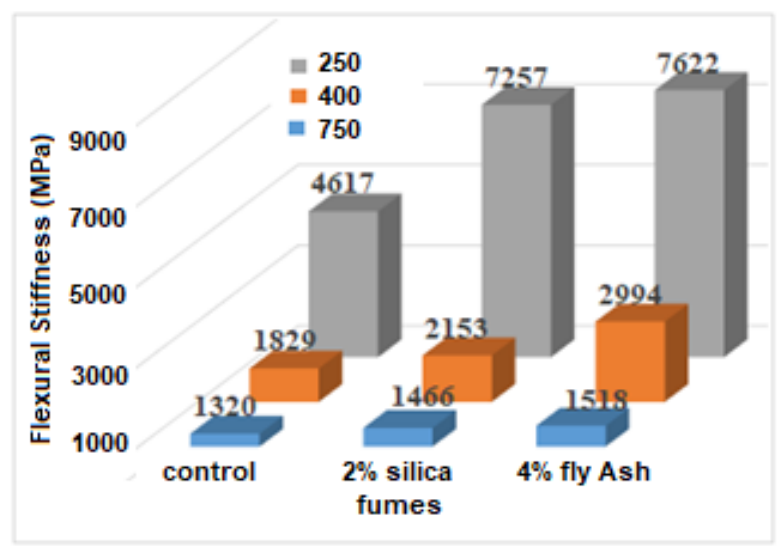

Figure 1. Influence of Additives on Flexural Stiffness

\subsection{Influence of additives on fatigue life of asphalt concrete}

Figure 2 exhibit the influence of additives on fatigue life of asphalt concrete. It can be noted that implementation of additives exhibits positive influence on the fatigue life of asphalt concrete regardless of the micro strain level implemented.

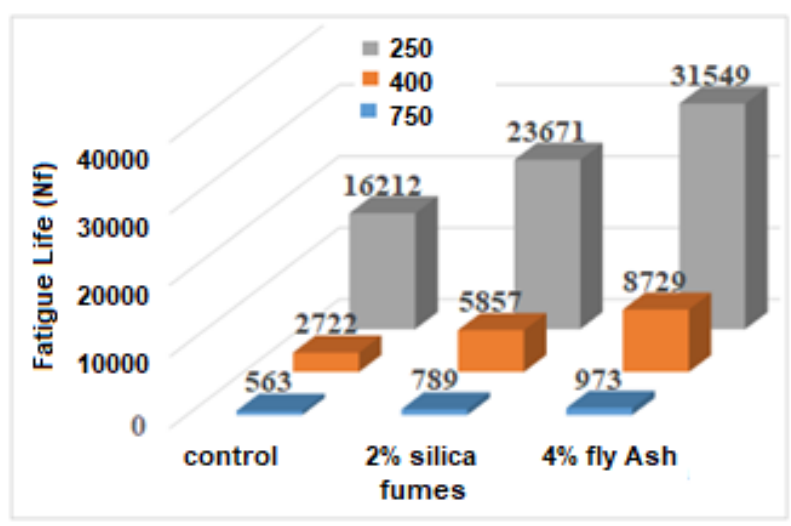

Figure 2. Influence of Additives on Fatigue Life 
However, as the strain level increases, the fatigue life decreases regardless of the additives implemented. The fatigue life increases by (40, and 72.8$) \%$, (115, and 220.6$) \%$, (46, and 94.6$) \%$ when $2 \%$ of silica fumes or $4 \%$ of fly ash are implemented and the specimen's practices 750,400 , and 250 micro strain levels respectively. On the other hand, when the strain level decline from 250 to 400 and 750, the fatigue life declines by (83.2, and 96.5), (75.2, and 96.6), (72.3, and 97) for control, modified mixture with $2 \%$ silica fumes and modified mixture with 4 $\%$ fly ash respectively. Such behavior agrees well with Sarsam and ALLamy, [12].

\subsection{Influence of additives on rate of deterioration of asphal concrete}

Figure 3 demonstrate the influence of additives on the rate of deterioration in the fatigue life of asphalt concrete, it can be noticed that the fatigue life increases after the implementation of additives. It can be noted that the fatigue life increases after implementing silica fumes and fly ash as additives respectively. Moreover, implication of additives exhibits a gentle deterioration in fatigue life as compared with control mixture. Table 9 shows that the slope declines from 0.326 for control mixture to 0.322 and 0.313 for silica fumes and fly ash treated mixtures respectively.

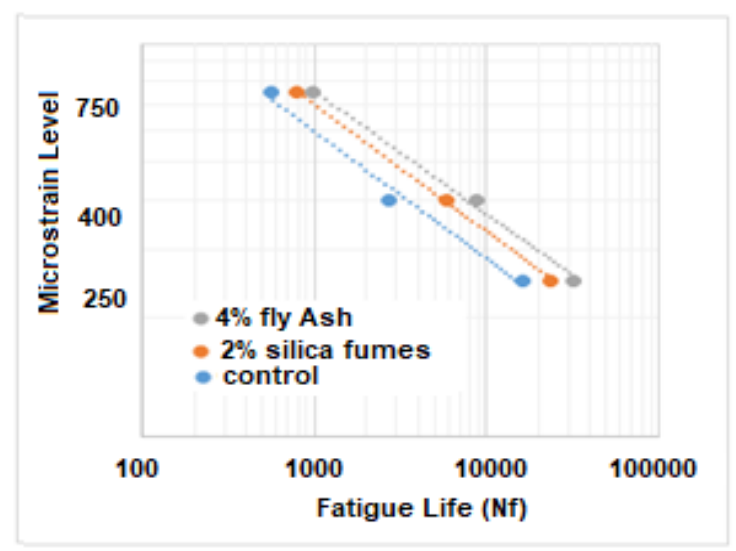

Figure 3. Influence of Additives on Rate of Deterioration in fatigue life of Asphalt Concrete

Table 9. Deterioration Parameters of Asphalt Concrete

\begin{tabular}{lccc}
\hline Mixture Type & Slope & Mathematical Model & $\mathrm{R}^{2}$ \\
\hline Control & -0.326 & $\mathrm{Y}=5663.5 \mathrm{X}^{-0.326}$ & 0.985 \\
$2 \%$ Silica Fumes & -0.322 & $\mathrm{Y}=6473.7 \mathrm{X}^{-0.322}$ & 0.999 \\
$4 \%$ Fly Ash & -0.313 & $\mathrm{Y}=6546.4 \mathrm{X}^{-0.313}$ & 0.995 \\
\hline
\end{tabular}

\section{Conclusions}

Based on the materials implemented and the limitation of testing program, the following conclusions can be drawn.

- The flexural stiffness increases by (11, and 15) \%, (17.7, and 63.6) $\%$, (57.2, and 65 ) $\%$ when $2 \%$ of silica fumes or $4 \%$ of fly ash are implemented and the specimen's practices 750,400 , and 250 micro strain levels respectively.

- The fatigue life increases by (40, and 72.8$) \%$, (115, and 220.6$) \%$, (46, and 94.6 ) \% when $2 \%$ of silica fumes or $4 \%$ of fly ash are implemented and the specimen's practices 750, 400, and 250 micro strain levels respectively.

- Implication of additives exhibits a gentle deterioration in fatigue life as compared with control mixture. The slope declines from
0.326 for control mixture to 0.322 and 0.313 for silica fumes and fly ash treated mixtures respectively.

- It is recommended to use modified binder with silica fumes and fly ash in asphalt concrete to enhance the fatigue life and stiffness.

\section{Declaration of Conflict of Interests}

The author declares that there is no conflict of interest. He has no known competing financial interests or personal relationships that could have appeared to influence the work reported in this paper.

\section{References}

[1.] Adhikari S., You Z. Fatigue Evaluation of Asphalt Pavement using Beam Fatigue Apparatus. The Technology Interface Journal/Spring. Volume 10 No. $3 . \quad$ (2010). http://technologyinterface.nmsu.edu/Spring10.

[2.] Kakade, V.B.; Reddy, M.A.; Reddy, K.S. Rutting performance of hydrated lime modified bituminous mixes. Constr. Build. Mater. 186, 1-10. (2018). https://doi.org/10.1016/j.conbuildmat.2018.07.009.

[3.] Al-Mohammedawi A. and Mollenhauer K. A Study on the influence of the chemical nature of fillers on rheological and fatigue behavior of bitumen emulsion mastic. Materials, 13, 4627; MDPI. doi:10.3390/ma13204627.

(2020). www.mdpi.com/journal/materials.

[4.] Lesueur, D.; Teixeira, A.; Lázaro, M.M.; Andaluz, D.; Ruiz, A. A simple test method in order to assess the effect of mineral fillers on bitumen ageing. Constr. Build. Mater. 117, (2016). 182-189. https://doi.org/10.1016/j.conbuildmat.2016.05.003.

[5.] Buczy' nski, P.; Iwa' nski, M. Inactive Mineral Filler as a Stiffness Modulus Regulator in Foamed Bitumen-Modified Recycled Base Layers. IOP Conf. Ser. Mater. Sci. Eng. 245, 032042. (2017). doi:10.1088/1757-899X/245/3/032042.

[6.] Underwood, B.S.; Kim, Y.R. Experimental investigation into the multiscale behavior of asphalt concrete. Int. J. Pavement Eng. 12, (2011). 357-370. https://doi.org/10.1080/10298436.2011.574136.

[7.] Khan A. A., Ullah N., Ahmad A., Ali S. Evaluation of mechanical properties of hot mix asphalt by replacing the combination of marble dust and silica fume as a filler. GSJ: Volume8, Issue 9 , September. P.681-690. (2020). www.globalscientificjournal.com

[8.] Ullah R., Hafeez I., Zaidi S., Jamal, and Safeer Haider S. Study the Effect of Substitution Filler on performance of Asphalt Mixture. Civil Engineering Journal Vol. 6, No. 9, September. (2020).www.CivileJournal.org.

[9.] Bahia, H., Hanson D. I., Zeng M., Zhai H., Khatri M., and Anderson R. Characterization of modified asphalt binders in Superpave mix design. No. Project 9-10 FY'96. (2001).

[10.] Wang. J., Guo M., and Tan Y. Study on application of cement substituting mineral fillers in asphalt mixture. International Journal of Transportation Science and Technology 7, no. 3, September. P. 189-198. (2018). doi: 10.1016/j.ijtst.2018.06.002.

[11.] Sarsam S. I. Influence of Aging, Temperature and Moisture Damage on the Stiffness of Asphalt Concrete through the Fatigue Process. International Journal of Scientific Research in Knowledge, 4(4), (2016). P. 077-084, http://www.ijsrpub.com/ijsrk. 
[12.] Sarsam S. I. and AL-Lamy A. K. Fatigue life assessment of Modified Asphalt Concrete. International Journal of Scientific Research in Knowledge, 3(2), (2015). P. 030-041. http://dx.doi.org/10.12983/ijsrk-2015-p0030-0041.

[13.] Tapkın S. Estimation of Fatigue Lives of Fly Ash Modified Dense Bituminous Mixtures Based on Artificial Neural Networks. Materials Research. 2014; 17(2): 316-325 (2014). P. 316-325. DDOI: http://dx.doi.org/10.1590/S1516-14392014005000040.

[14.] ASTM. American Society for Testing and Materials, ASTM: Road and Paving Material, Vehicle- Pavement System, Annual Book of ASTM Standards, Vol. 04.03. (2016). www.astm.org.

[15.] SCRB. State Commission of Roads and Bridges. Standard Specification for Roads \& Bridges, Ministry of Housing \& Construction, Iraq. (2003).

[16.] AASHTO T-321. Method for Determining the Fatigue Life of Compacted Hot-Mix Asphalt (HMA) Subjected to Repeated Flexural Bending, AASHTO Provisional Standards. (2010) Washington, D.C.

[17.] Sarsam S. I. and Alwan A. H. Assessing Fatigue Life of Super Pave Asphalt Concrete. American Journal of Civil and Structural Engineering AJCSE (2014), 1(4):88-95.

[18.] EN 12697- 33, Bituminous Mixtures - Test Methods for Hot Mix Asphalt - part 33: Specimen prepared by Roller Compactor, (2007). European Committee for Standardization.

\section{How to Cite This Article}

Sarsam S. I., Assessment of Fatigue Life and Stiffness of Asphalt Concrete After Implementation of Additives, Civil Engineering Beyond Limits, 4(2021),8-12.

https://doi.org/10.36937/cebel.2021.004.002. 